Indian J Anim Health (2021) , 60(2): 287-289

DOI: https://doi.org/10.36062/ijah.2021.04921

\title{
Successful surgical removal of foreign body from stomach of a puppy:
}

\section{A case report}

\author{
M. Sharma ${ }^{1 *}$, B. K. Sarma ${ }^{1}$, R. Devi ${ }^{1}$ and P. Thakuria ${ }^{1}$ \\ ${ }^{1}$ Department of Veterinary Clinical Complex, Lakhimpur College of Veterinary Science, Assam \\ Agricultural University, Joyhing, North Lakhimpur - 787 051, Assam, India

\begin{abstract}
This communication represents a case of successful removal of foreign body from the stomach of a 3 to 4 months old Golden Retriever male puppy by laparo-gastrotomy, presented to the Veterinary Clinical Complex, with a definite history of eating a makeup sponge 2 days before the day of presentation. The animal was subjected to surgical removal after visualization of the object under both plain and contrast abdominal radiography. Careful routine post-operative fluid therapy and medicinal management could bring uneventful recovery and the puppy started taking normal food without any post-operative complications within one month.
\end{abstract}

Key words: Contrast radiography, Foreign body, Laparo-gastrotomy, Puppy, Stomach

Playful nature of young dogs or puppies often leads to the incidence of foreign body ingestion (Kumar et al., 2000; Capak et al., 2001; Papazoglou et al., 2003). Obstruction of gastro-intestinal tract by foreign bodies like rubber objects, metallic objects, plastic objects, stones, etc. have already been reported by many authors worldwide (Koike et al., 1981; Raghunath et al., 2016; Mahesh et al., 2019). Foreign body passing through esophagus and stomach may lead to serious life-threatening complications due to acid-base and electrolyte imbalances from severe fluid loss or hypovolemia, and toxemia (Papazoglou et al., 2003; Fossum, 2012), however, foreign body lodging in gastric fundus without obstructing the pylorus may not show any clinical sign of foreign body syndrome (Halder et al., 2018; Bharathidasan et al., 2019). Laparo-gastrotomy is the only option to remove a foreign body from the stomach when endoscopy is not available or endoscopic removal of foreign body is not possible. This communication describes a successful surgical removal of makeup sponge by laparo-gastrotomy from the stomach of a male puppy.
A 3 to 4 months old male dog weighing $5.1 \mathrm{~kg}$ was presented to the Veterinary Clinical Complex with a confirmed history of eating a makeup sponge 2 days ago from the day of presentation. The owner reported that the puppy did not show any other gastrointestinal tractrelated symptoms except a mild decrease in appetite. Anamnesis also revealed that despite normal defecation the sponge was not found in faeces.

Clinical evaluation revealed a normal study with mild dehydration. A doughy mass could also be felt on the abdominal ballottement. Further, the puppy was subjected to both plain and contrast abdominal lateral radiography which confirmed the presence of the sponge in the stomach (Fig. 1). Laparo-gastrotomy was decided as purgative administration could not remove the sponge.

Ringer's lactate $50 \mathrm{~mL}$ intravenously (IV) was administered twice daily for the previous two days of surgery. Ceftriaxone @ $25 \mathrm{mg} / \mathrm{kg}$ body weight (BW) and pantoprazole @ $1 \mathrm{mg} / \mathrm{kg} \mathrm{BW}$ as an antibiotic umbrella and a safeguard of gastrointestinal tract mucosa respectively were also given IV on the previous

*Corresponding Author, E mail: manavs46@aau.ac.in 
day of surgery. The puppy was fasted for 12 hours. Total intra venous anaesthesia (TIVA) protocol was followed for anaesthetic management (Sharma et al., 2021). As preanaesthetic, glycopyrolate @ $0.01 \mathrm{mg} / \mathrm{kg} \mathrm{BW}$ IV and diazepam @ $0.5 \mathrm{mg} / \mathrm{kg}$ BW IV were administered. General anaesthesia was induced by propofol @ $4 \mathrm{mg} / \mathrm{kg} \mathrm{BW} \mathrm{IV} \mathrm{following} \mathrm{till}$ effect.

Endotracheal intubation was also done to maintain a patent airway. Anaesthetic maintenance was done by 1:1 ratio mixture of ketamine and diazepam through IV route. Following aseptic surgical preparation of the entire ventral abdominal area, a cranial mid ventral incision through the skin, subcutaneous tissue and linea-alba was given. After exteriorizing the stomach, the laparotomy wound was packed by sterile draper dipped in normal saline and two stay sutures were applied (Fig. 2). The sponge was removed via a linear incision on the ante mesenteric end avoiding major vessels (Fig. 2a). The gastrotomy wound was closed by placing simple continuous suture using 4-0 chromic catgut between the submucosa and muscularis layer (Slatter, 2003; Iqbal et al., 2020) followed by a layer of Cushing suture using 3-0 catgut over the serosa. The laparotomy wound was closed by $1-0$ polyglactin 910 and no. 1 black braided silk suture material on linea-alba and skin respectively (Fig. 2b). The puppy was maintained on IV fluids and medicinal therapy for another 5 days. Ringer's lactate (RL)- 50 $\mathrm{mL}$ and dextrose normal saline (DNS)- $50 \mathrm{~mL}$ in morning and evening respectively were infused intravenously for these 5 days along with other medicinal support like ceftriaxone @ $25 \mathrm{mg} / \mathrm{kg} \mathrm{BW} \mathrm{IV,} \mathrm{pheniramine} \mathrm{maleate} \mathrm{@}$ $0.5 \mathrm{mg} / \mathrm{kg}$ BW IM from $5^{\text {th }}$ post-operative day for another 5 days, pantoprazole @ $1 \mathrm{mg} / \mathrm{kg}$ BW IV, tramadol@2 mg/kg BW IV and vitamin B-complex @ $1 \mathrm{~mL} /$ day IV for 7 days. The surgical wound was dressed regularly by povidone iodine liquid and ointment from $3^{\text {rd }}$ post-operative day onwards till suture removal. Sutures were removed on the $10^{\text {th }}$ day postsurgery and the dry dressing was also continued for another 3-4 days. From the $6^{\text {th }}$ day onward rice gruel, vegetable soup, oats were offered for another 2-3 days followed by normal solid food as a progressive development in appetite was noticed. Without any post-operative complications, the puppy recovered within one month.

Progressive development in appetite and gradual return to normal health could finally bring uneventful recovery within one month.

Gluttonous or indiscriminate feeding habits with curious and playful nature of young puppy generally leads to ingestion of non-dietary item as seen in this case (Papazoglou et al., 2003; Raghunath et al., 2016; Bharathidasan et al., 2019). However, obstruction of GIT as well as the pattern of clinical sign depends on the location, degree and duration of obstruction as well as size and nature of foreign bodies (Sajeni et al., 2017; Halder et al., 2018; Bharathidasan et al., 2019); again, if the foreign body lodges in the fundus without blocking pylorus typical signs of GIT obstruction or foreign body syndrome may not be seen (Halder et al., 2018; Bharathidasan et al., 2019). Absence of clinical sign in the present case was probably due to the same reason mentioned above. Both plain survey X-ray and a confirmatory contrast Xray were done to verify the presence and site of the sponge respectively in this case. The corroborative observation was also made by Papazoglou et al. (2003) and Bharathidasan et al. (2019). As reported by other authors foreign body removal by laparo-gastrotomy is often indicated and has a good prognosis (Bharathidasan et al., 2019). Following GIT surgery post-operative endurance is always challenging for the veterinarian as the animal needs to keep in continuous parental feeding or fluid therapy for the next few days. To maintain electrolyte balance, improving tissue perfusion and body homeostasis post-operative fluid therapy is usually aimed for the first few days with Ringer's lactate and dextrose normal saline in the present case. Similar approaches in case of GIT surgery were also made by Papazoglou et al. (2003), Patil et al. (2010), Raghunath et al. (2016) and Nandini et al. 
Indian Journal of Animal Health, December, 2021

Surgical removal of foreign body of a puppy

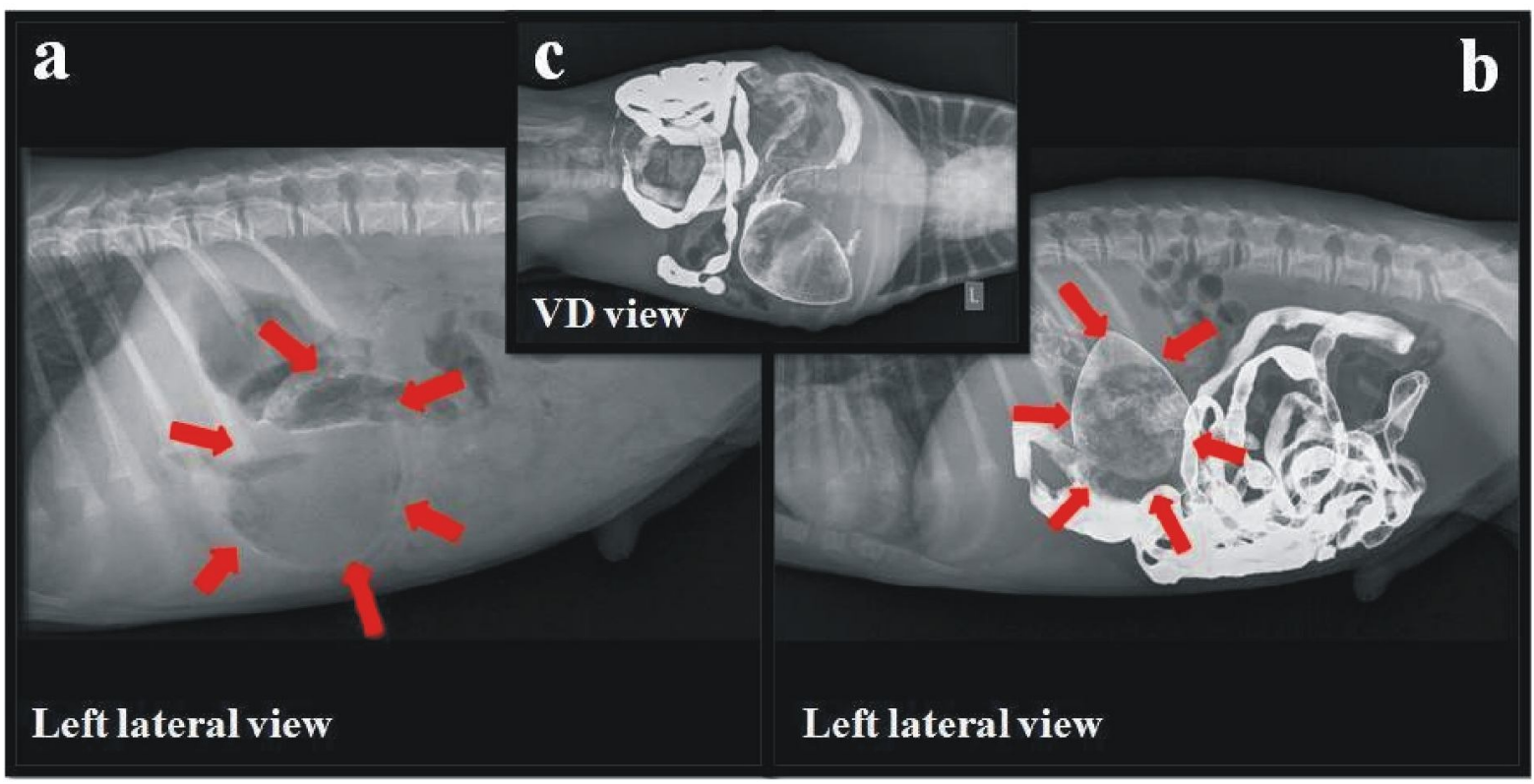

Fig. 1. Images representing radiographic diagnoses (red arrows showing the outline of sponge) a) Plain radiography, b) \& c) Barrium contrast radiography

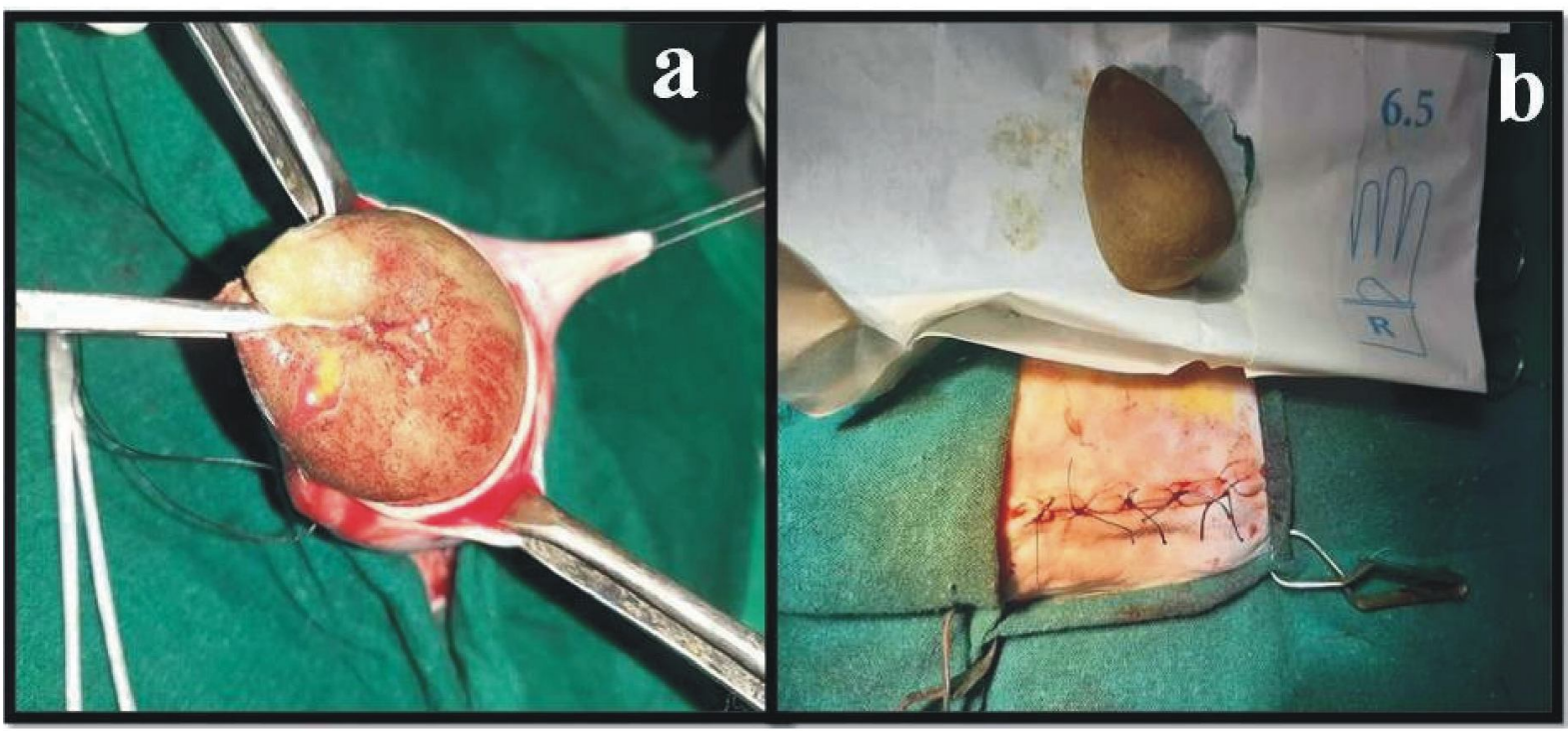

Fig. 2. Images representing peri-operative procedure, a) Removal of sponge from via linear gastric incision and stay suture, b) Cross Mattress skin suture and the recovered sponge 
(2017). As reported by Patil et al. (2010) and Halder et al. (2018) prognosis of GIT surgery depends upon the duration of presentation, site of obstruction and severity of clinical signs. In this case too timely presentation, absence of blockage and absence of clinical signs probably resulted in positive.

The authors of this communication would like to draw a conclusion from the

\section{REFERENCES}

Bharathidasan M, Kokila S, Vishnugurubaran D, Ninu AR, Dharmaceelan S et al., 2019. Surgical retrieval of gastric-shuttlecock in Golden Retriever dog. Int J Agri Sci, 11(1): 7713-7714

Capak D, Brkić A, Harapin I, Matičić D and Radišić B, 2001. Treatment of the foreign body induced occlusive ileus in dogs. Vet Arhiv, 71(6): 345-359

Fossum TW, 2012. Small Animal Surgery. Elsevier Health Sciences, $4^{\text {th }}$ edn., St. Louis, pp 516-528

Halder S, Mandal D and Sarkar P, 2018. Laparogastrotomy for removal of gastric metallic bolt in spitz dog. Intas Polivet, 20(1): 135-136

Iqbal N, Hussain N, Atif M, Aslam S, Jawad H et al., 2020. Comparative efficacy of sutures and suture less techniques for gastrotomy incision closure in dog. Adv Anim Vet Sci, 8(12): 1294-1300, doi: 10.17582/journal.aavs/2020/8.12.1294.1300

Koike T, Otomo K, Kudo T and Sakai T, 1981. Clinical cases of intestinal obstruction with foreign bodies and intussusception in dogs. Jpn J Vet Res, 29(1-2): 8-15, doi: 10.14943/jjvr.29.1-2.8

Kumar DD, Ameerjan K and David WA, 2000. Gastro intestinal tract obstruction in dogs. Ind J Vet Sur, 2(1): 43-44

Mahesh V, Kamalakar G and Nagaraja BN, 2019. Enterotomy in a Labrador Retriever - A case report. Int J Livest Res, 9(12): 240-243, doi: 10.5455/ ijlr.20190920035701 aforementioned report that timely presentation, aseptic surgical intervention along with careful routine post operative fluid and medicinal therapy could bring uneventful recovery following a laparo-gastrostomy surgery in canine.

Conflict of interest: Authors have no conflict of interest in this study.

Nandini MK, Vishwakarma P and Mahesh V, 2017. Gastrointestinal obstruction due to linear foreign body in a cat: A case report. Adv Anim Vet Sci, 5(10): 416-418, doi: 10.17582/journal.aavs/2017/ 5.10.416.418

Papazoglou LG, Patsikas MN and Rallis T, 2003. November intestinal foreign bodies in dogs and cats. Compend, 25(11): 830-844

Patil DB, Parikh PV, Jhala SK, Tiwari DK and Dar MUD, 2010. Gastric foreign bodies in dogs - A report of five cases. Intas Polivet, 11(2): 297298

Raghunath M, Sagar PV, Sailaja B and Kumar PR, 2016. Surgical correction of intestinal obstruction in a German Shepherd dog. Scholars J Agri Vet Sci, 3(3): 187-189

Sajeni S, Reisinger W, Mushonga B, Kandiwa E and Habarugira G, 2017. Foreign Body gastrotomy in an adult captive cheetah, Acinonyx jubatus. Alex J Vet Sci, 52(1): 148-152, doi: 10.5455/ ajvs.231231

Sharma M, Baishya MP, Sampurna NY, Sarma BK, Devi R et al., 2021. Successful surgical correction of intestinal foreign body obstruction in canine: A case report. Haryana Vet, 60(SI): 94-96

Slatter D, 2003. Textbook of Small Animal Surgery, Saunders, Elsevier Health Sciences, $3^{\text {rd }}$ edn., Vol.1, Philadelphia, PA 19106, USA, pp 597

Received 20.05.21, Accepted - 29.06.2021, Published - 01.09.2021 (Online), 01.12.2021 (Print) Section Editor: Prof. S. K. Nandi, Associate Editor 